Revista de Derecho

de la Pontificia Universidad Católica de Valparaíso

52 (primer semestre de 2019)

[pp. $101-128$ ]

\title{
LIBERTAD COMO NO-INTERFERENCIA Y ABOGACÍA
}

[Lawyering and Freedom as Non-interference]

\author{
Hugo Omar Seleme* \\ Universidad Nacional de Córdoba, Argentina
}

\begin{abstract}
RESUMEN
En los sistemas adversariales el abogado se encuentra sujeto a deberes en tensión. Por un lado, debe lealtad a los intereses del cliente al que representa. Por el otro, debe lealtad a los intereses de la comunidad política corporizados en el sistema jurídico. La manera en que estas lealtades se acomodan y articulan, define los contornos del rol profesional. El objetivo del presente trabajo es mostrar que la manera en que el rol profesional se encuentra actualmente configurado, y la manera en que se ha resuelto la tensión entre la lealtad privada y la pública, descansa en una manera de concebir la libertad como no-interferencia.
\end{abstract}

Palabras clave

Ética jurídica - lealtad - Isaiah Berlin - instrumentalismo.

\section{ABSTRACT}

Adversarial systems impose conflicting demands on lawyers. On the one hand, they must be loyal in the interest to their clients. On the other, they must be loyal to the political community and must to promote the public interests embodied in the legal system. The way in which these loyalties are accommodated and articulated, defines the contours of the professional role. The objective of this paper is to show that the way in which the professional role is currently configured, and the way in which the tension between private and public loyalty has been resolved, rests in a particular way of conceiving freedom as non-interference.

\section{KEY WORDS}

Legal ethics - loyalty - Isaiah Berlin - instrumentalism.

RECiBIDO el 26 de julio de 2018 y APROBADO el 7 de enero de 2019

* Doctor en Derecho y Ciencias Sociales por la Universidad Nacional de Córdoba (Argentina). Investigador del CONICET (Argentina). Catedrático de Ética, Facultad de Derecho, Universidad Nacional de Córdoba. Director del Programa de Ética y Teoría Política, Universidad Nacional de Córdoba. Dirección electrónica: hugoseleme@conicet.gov.ar 


\section{INTRODUCCIÓN}

Ningún rol profesional o laboral está exento de albergar exigencias en potencial conflicto. Esto no es más que una consecuencia de la complejidad de los roles -configurados por múltiples requerimientos- y de la pluralidad de circunstancias en las que deben ser ejercitados -lo que acrecienta la posibilidad de encontrar situaciones donde los requerimientos colisionen-. En el caso del rol de abogado, sin embargo, el problema se exacerba porque parece estar configurado por lealtades aparentemente antagónicas. En los sistemas adversariales el abogado ocupa una posición intermedia entre el dominio privado - corporizado en los intereses particulares del cliente al que representa- y el dominio público - patentizado en los intereses de la sociedad o del sistema jurídico al que pertenece- que somete su actuación a fuerzas encontradas ${ }^{1}$.

Por un lado, el abogado debe a su cliente lealtad en los intereses. Este tipo de lealtad exige priorizar los intereses de otro esforzándose en que sus deseos y preferencias sean satisfechos. Philip Pettit, por ejemplo, afirma que ser leal a alguien equivale a estar “...dedicado al bienestar de un individuo en particular..."2. En el caso del abo-

${ }^{1}$ El hecho de que el trabajo se concentre en el rol profesional del abogado en el seno del sistema adversarial implica un recorte en el objeto de estudio. De las múltiples funciones que puede desempeñar un abogado -asesor, litigante, representante, funcionario, etc.- la que interesa aquí es la que lleva adelante en el marco del proceso judicial. Dada la importancia que tiene esta función, lo que se diga sobre ella tendrá impacto sobre el resto de los roles que puede desempeñar un abogado fuera del proceso o dentro del proceso como funcionario público. No obstante, los roles de asesor y de defensor público poseen peculiaridades propias que no son objeto de estudio en el presente trabajo. Agradezco a un árbitro anónimo el haberme hecho notar la necesidad de introducir esta aclaración.

${ }^{2}$ PetTit, Philip, The Instability of Freedom as Noninterference: The Case of Isaiah Berlin, en Ethics 121 (2011). Pettit caracteriza de este modo a la lealtad en general. Creo que se trata de un error dado que existe otro tipo de lealtad -la referida a las creencias- que no se refiere a la promoción de los intereses o el bienestar de otro. Como señala Keller, priorizar los intereses de un individuo no es ni necesario ni suficiente para mostrar lealtad hacia él; Keller, Simon, The Limits of Loyalty (Cambridge, Cambridge University Press, 2007), p. 9. No es suficiente porque uno puede priorizar los intereses de alguien por consideraciones distintas a las vinculadas con la lealtad, por ejemplo por consideraciones impersonales vinculadas con la justicia de su reclamo. No es necesario porque existen manifestaciones de lealtad que no están vinculadas con la promoción de intereses. Alguien es leal en 
gado, la relación profesional que entabla con el cliente requiere que defienda los intereses de éste como si fuesen los suyos propios ${ }^{3}$.

Por otro lado, el abogado debe también lealtad a la sociedad toda y a sus intereses, expresados a través del sistema jurídico. En este sentido, no es sólo un vocero, un representante o un promotor de los intereses particulares de su cliente, sino que también debe velar por la satisfacción de los intereses colectivos o el bien común, protegiendo la integridad del entramado institucional. La exigencia de lealtad a los intereses colectivos que pesa sobre los abogados los asemeja a los funcionarios públicos y, aparentemente, entra en competencia con la lealtad debida al cliente.

La presencia de estas dos exigencias de lealtad, como es obvio, da lugar a tensiones y conflictos. Refiriéndose a la ubicuidad de este

relación con otro, por ejemplo, por identificarse con él. En esta manifestación de lealtad la persona leal "...trata el objeto al cual ella es leal como si fuese ella misma, sintiendo y actuando como lo haría ciertas cosas que son verdaderas en relación con él fuesen verdad en relación con ella...” (p. 6). Otra expresión de lealtad no vinculada con la promoción de intereses tiene que ver con la defensa de aquel a quien se debe lealtad. Si alguien está hablando mal de un amigo, por ejemplo señalando lo incompetente que es, la lealtad exige cuestionar lo que se está diciendo. Esto con total independencia de que esto no tenga ningún impacto en la promoción de sus intereses. Otros modos de expresar lealtad están relacionados con la participación en rituales. Para una persona casada usar el anillo que intercambio con su pareja es una manifestación de lealtad, aunque esto no tenga ningún impacto en la promoción de los intereses del otro (p. 5). Finalmente, la lealtad en las creencias es un tipo de lealtad no vinculada con la promoción de intereses. La lealtad a alguien es expresada como lealtad en las creencias si "...ser leal a X lo inclina a ud. a sostener o rechazar ciertas creencias, independientemente de la evidencia...” (p. 6) .

${ }^{3}$ Junto con esta lealtad en los intereses el abogado le debe a su cliente lealtad en las creencias. Me he ocupado de defender esta posición en otro lugar; SELEME, Hugo, Ética de las Creencias y Defensa Legal, en Salassa Boix, R. - Fatauros, C. (eds.), Instituciones Públcias y Moralidad Política (Córdoba, Ciencia, Derecho y Sociedad UNC, 2014). Allí he sostenido que la exigencia de ser deferente a las opiniones del cliente con respecto a su inocencia pone de manifiesto que aquel con quien el abogado trata es un agente sensible a razones que puede examinarse a sí mismo y cuyo juicio posee relevancia. Proceder de otro modo equivale a tratarlo como un mero objeto cuyas opiniones acerca de su situación no cuentan. El abogado que mira con desconfianza cualquier declaración formulada por su cliente priva a la profesión de su carácter humanista y, adicionalmente, socava al proceso judicial de cualquier atisbo de legitimidad.

${ }^{\text {A }}$ los fines de este trabajo, sin embargo, me concentraré exclusivamente en la lealtad en los intereses que el abogado debe a su cliente, dejando de lado los conflictos que pueden aparecer en base a la lealtad en las creencias. 
problema dentro de la cultura legal estadounidense, y a la dificultad para encontrarle una respuesta, William Simon señala: “...En la tradición jurídica estadounidense el abogado siempre ha sido a la vez partisano del cliente y un 'funcionario de la corte'. Nunca ha existido consenso sobre donde trazar la línea entre estos dos aspectos del rol de abogado, y los dos siempre han estado en tensión dentro de la cultura profesional" ${ }^{4}$. El problema de dónde deben trazarse los límites entre la lealtad debida al cliente y la debida a la comunidad, como tendremos oportunidad de ver, no ha sido propiedad exclusiva de la cultura legal estadounidense.

El objetivo del presente trabajo es, en primer lugar, identificar un modo peculiar de resolver la tensión entre ambas lealtades que ha conducido, a su vez, a configurar el rol de abogado. En segundo lugar, se pretende mostrar que éste modo de resolver las exigencias conflictivas de lealtad que pesan sobre el abogado, y la configuración del rol profesional que han producido, descansa en una manera de concebir la libertad como no-interferencia.

\section{CONFLiCTO DE LEALTADES Y ROL PROFESIONAL}

Las diferentes maneras en que estas exigencias de lealtad potencialmente conflictivas se acomodan determinan las diferentes formas de concebir el rol del abogado. El modo estándar de resolver la tensión entre ambas lealtades, ha configurado los actuales contornos del rol profesional. La respuesta estándar se caracteriza por diferentes elementos. En primer lugar, el abogado se percibe como un celoso defensor de la libertad de su cliente. Esto es así no sólo cuando la asistencia profesional tiene por objeto evitar la aplicación de una condena penal, sino también cuando lo que está en juego son intereses pecuniarios. Existe una vinculación, cuyas razones rara vez son articuladas, entre la idea de que el abogado debe promover celosamente, utilizando todos los recursos legales a su alcance, los intereses del cliente, y la idea de que es un defensor de su libertad. Sin importar cuál sea el contenido de estos intereses -y que estén vinculados o no con la libertad ambulatoria- su celosa defensa es equivalente a la defensa de la libertad.

El único límite que existe a la promoción de los intereses, esto es los únicos intereses de su cliente que no deben ser promovidos por el abogado, son aquellos que se oponen a las normas jurídicas. Por el contrario,

${ }^{4}$ Simon, William, The Practice of Justice: A Theory of Lawyer's Ethics (Cambridge, Harvard University Press, 1998), p. 63. 
cualquier recurso legal que utilice el abogado para mostrar que los intereses de su cliente no son contrarios a derecho, es aceptable. El abogado debe esforzarse "celosamente" para conseguir que los intereses de su cliente puedan encontrar el curso legal adecuado para ser satisfechos 5 . El límite al "celo" que el abogado debe poner en la defensa, no es otro que el que traza la frontera entre lo legal y lo ilegal.

En segundo lugar, y vinculado con lo anterior, el abogado brinda sólo asistencia técnica para que el cliente pueda ver satisfechos sus intereses. No es tarea del abogado juzgar, evaluar y menos aún intentar modificar, los intereses que su cliente posee. El rol del abogado es el de un mero técnico que brinda auxilio al cliente para que pueda llevar adelante sus fines. Dado que los fines que promueve el abogado no son los propios sino los de su cliente, y dado que su tarea no es evaluarlos, toda la responsabilidad moral por la elección de los fines recae en este último. David Luban denomina a este aspecto del rol profesional "partisana neutralidad". Esta especie de neutralidad requiere "... que los abogados permanezcan moralmente neutros en relación con los fines legalmente correctos del cliente, refrenándose de levantar su dedo acusador frente al cliente o de lanzar sus golpes motivados por la aprensión moral (...). En consecuencia, los abogados cuando actúan en su rol profesional no pueden ser tenidos como moralmente responsables por los fines del cliente y los medios que utilizan para perseguirlos..."6.

En tercer lugar, existe una confianza, al menos sobre el papel, en que este modo de proceder no sólo garantizará la satisfacción de los intereses privados del cliente sino también el interés público de la sociedad. Si cada cliente cuenta con un abogado que defiende sus intereses de manera "celosa”, por todos los medios legales a su alcance, la justicia será alcanzada. El sistema adversarial actúa como una especie de mano invisible que garantiza que cada uno persiguiendo sus intereses particulares, contribuya a alcanzar un resultado que es justo para todos. El sistema adversarial se presenta como un caso de justicia procesal pura ${ }^{7}$, cuyo mero funcionamiento garantiza la

${ }^{5}$ El autor denomina a esta manera de caracterizar el rol de abogado, la "visión dominante". Su tesis es que la regulación de la conducta profesional en Estados Unidos se encuentra fundada en esta "visión dominante" cuyo principio central señala que "...el abogado debe $-\mathrm{o}$ al menos puede- perseguir cualquier objetivo del cliente a través de cualquier curso de acción que pueda argumentarse como legal y sostener cualquier pretensión legal que no sea frívola ..."; SimON, cit. (n. 4), p. 7.

${ }^{6}$ Luban, David, Legal Ethics and Human Dignity (Cambridge, Cambridge University Press, 2007), p. 9.

${ }^{7}$ Rawls, John, A Theory of Justice (Cambridge, Harvard University Press, 1999), p. 74; la idea de justicia procesal pura procede de Rawls, quien la contrapone con la justicia procesal perfecta o imperfecta, donde sí existen criterios de evaluación de los resultados que son independientes del proceso que los ha producido. 
corrección de los resultados que provoca, sin que exista un criterio externo al proceso para evaluarlos ${ }^{8}$.

En cuarto lugar, el modo de percibir las normas jurídicas que se sigue de la "celosa defensa" es también la manera en que se perciben las normas que regulan la conducta profesional. Los abogados tienden a utilizar cualquier herramienta legal que permita circunvalar su aplicación. Ven con recelo cualquier intento de introducir estándares jurídicos que regulen la conducta profesional, invocando un difuso ideal de auto-regulación. Este ideal puede adoptar diferentes formas, las que van desde las posiciones que defienden el control de la conducta de los abogados por los estándares dictados por los colegios profesionales hasta quienes sostienen una especie de auto-regulación a través del mercado. Adicionalmente, los estándares regulativos se encuentran focalizados en identificar y prevenir los conflictos de intereses. El problema ético por antonomasia parece ser el que se presenta cuando el abogado y el cliente poseen intereses en conflicto, o cuando el conflicto se presenta entre los intereses de dos clientes del mismo abogado?.

Finalmente, en quinto lugar, sea que los parámetros que rigen la con-

${ }^{8}$ Por supuesto que existen otras defensas del sistema adversarial que, a diferencia de la que me interesa explorar aquí, apelan a la idea de justicia procesal imperfecta. Para quienes utilizan este tipo de justificaciones el sistema adversarial ayuda, por ejemplo, a corregir los sesgos en la presentación de los hechos, y promueve así el descubrimiento de la verdad; o ayuda a identificar cual es la interpretación de las normas jurídicas que se encuentra fundada en las mejores razones, y promueve así la aplicación al caso de estándares jurídicos genuinos. El referente paradigmático de quienes han intentado justificar el sistema adversarial como una herramienta para encontrar la verdad, es Fuller, Lon, The Adversary System: Talks on American Law (New York, Vintage Books, 1961). También puede encontrarse una defensa que se ha vuelto canónica en Freedman, Monroe, Judges Frenkiel's Searches for Truth, en University of Pennsylvania Law Review 123 (1985). En este ensayo Freedman intenta contrarrestar los ataques que Frankel dirige al sistema adversarial en base a su pobre desempeño como recurso que busca garantizar la verdad; Frankel, Marvin, The Search for Truth: An Umpireal View, en University of Pennsylvania Law Review 123 (1975). Entre quienes ofrecen una defensa del sistema adversarial como herramienta para encontrar el argumento jurídico más poderoso, se destaca HAMPSHIRE, Stuart, Justice is Conflict (Princeton, Princeton University Press, 2001).

${ }^{9}$ Lerman, Lisa - Schrag, Philip, Ethical Problems in the Practice of Law (2 edición, New York, Aspen Publishers, 2008), p. 353; los autores ponen de manifiesto esta tendencia a focalizar los problemas éticos en los conflictos de intereses cuando señalan que: “...una de las habilidades más importantes que necesitaras como abogado es la de identificar y analizar conflictos. Algunos grandes bufetes tienen uno o más abogados especialistas cuya principal función es la de evaluar conflictos potenciales o actuales ...”. Lo que llama la atención en esta aseveración es que se asume que el rol del "experto en ética" es identificar potenciales conflictos, dando a entender que este es el problema ético más acuciante que afrontan los abogados. 
ducta profesional surjan por un proceso de auto-regulación, a través de los colegios profesionales o a través de la mano invisible del mercado, o sea que estos sean impuestos por los órganos del Estado, estas pautas regulativas sólo exigen ciertas conductas dejando de lado por completo la exigibilidad de ciertos rasgos de carácter. La idea de un abogado dotado de rasgos de carácter valiosos, esto es la idea de un abogado virtuoso, es reemplazada por la de uno apegado a las reglas. Presentado en términos técnicos la ética profesional es vista como una "ética de principios" focalizada en las reglas y no como una "ética de la virtud o el carácter" ${ }^{10}$. Para ser un buen abogado no se requiere prudencia o sabiduría práctica -que permita a la vez identificarse empáticamente con la posición del cliente y ditanciarse de ella para brindar consejo o diseñar estrategias de litigio ${ }^{11}$ - ni un sentido de la justicia-que permita distinguir entre los intereses legítimos e ilegítimos del cliente- ni misericordia - para ayudar al cliente a resignar sus pretensiones legales cuando pueden causar daño a terceros- ni amistad cívica ${ }^{12}$ o veracidad ${ }^{13}$. Lo único que es necesario es conocer las reglas y seguirlas ${ }^{14}$.

En síntesis, el modo estándar de acomodar las dos exigencias de lealtad

${ }^{10}$ Han sido muchos quienes han llamado recientemente la atención sobre este rasgo de la ética profesional. Entre los más destacados se encuentran Kronman, Anthony, The Last Lawyer: Failing ideals of the Legal Profession (Cambridge, Harvard University Press, 1995) y Glendon, Mary Ann, A Nation Under Lawyers (Cambridge, Harvard University Press, 1996).

${ }^{11}$ Kronman piensa que esta es la virtud central de jueces y abogados. Sin embargo, denuncia, los estudios jurídicos han dejado de cultivarla, y los jueces han dejado de ejercerla debido al poco tiempo que tienen para analizar los casos que se van acumulando; Kronman, cit. (n. 10), p. 354.

${ }^{12}$ La pérdida de las virtudes cívicas por parte de los abogados, los jueces y los profesores de derecho, es el tema central del libro de Glendon. La descripción que ofrece de éstos, y el riesgo que implican para la democracia, es elocuente. En su opinión se trata de "...jueces con grandilocuentes visiones de la autoridad judicial, abogados ansiosos por abrir nuevos senderos a los atestados tribunales de la nación, y profesores de derecho que anhelan ser filósofos reyes y reinas..."; GLENDON, cit. (n. 10), p. 382.

${ }^{13}$ ShafFer, Thomas - Cochran, Robert, Lawyers, clients and moral responsibility (St. Paul, West Publishing, 1994), p. 81; los autores han defendido esta posición. En su opinión los abogados deberían "...contarle a sus clientes acerca del riesgo que si dejan que su actitud competitiva hacia la parte contraria domine por complete, entonces se transformará en un odio destructivo y corrosivo".

${ }^{14}$ En Estados Unidos la tendencia a focalizarse en las reglas se ha visto reforzada por la aparición de escándalos públicos en los que han estado involucrados abogados. El más resonante sin dudas fue Watergate que provocó que la American Bar Associaton adoptase un nuevo conjunto de reglas más detalladas en 1983 para reemplazar el Código Modelo de 1974 y la mayoría de las universidades introdujesen cursos de ética profesional en su currícula. Esta tendencia, como es obvio, no ha sido 
pública y privada que caracterizan la tarea del abogado configura el rol profesional con cinco características: el abogado debe llevar adelante una "celosa defensa" de los intereses y la libertad del cliente dentro de los límites de la ley, su función es meramente técnica, la defensa de los intereses privados contribuye a la promoción del interés público o a la realización de la justicia, cualquier intento de regular heterónomamente el ejercicio profesional es visto con desconfianza, y la ética profesional está focalizada en los conflictos de intereses y es percibida como una "ética de principios o reglas".

\section{El CONFLICTO EN LOS CÓDIGOS DE ÉTICA}

Las exigencias potencialmente conflictivas que surgen de la lealtad que el abogado le debe a los intereses de su cliente y la que debe a los intereses colectivos expresados en el sistema jurídico, no sólo han sido objeto de análisis teórico sino que se encuentra reflejada en las normas que regulan el ejercicio profesional. Lo mismo sucede con las características del rol profesional antes enunciadas, que se siguen de un modo específico de resolver la tensión que existe entre las diferentes exigencias de lealtad. La diversidad de sistemas regulatorios que receptan en su normativa ambos tipos de exigencias y el modo recién presentado de conciliarlas, muestra que tanto el problema como su respuesta no es patrimonio de una cultura jurídica específica.

Por lo que respecta al primer tipo de lealtad, aquella que el abogado le debe al cliente, su positivización ha alcanzado la vasta mayoría de los códigos de ética profesional. Así, por ejemplo, el Model Code of Professional Responsibility de 1974 de la America Bar Association en su consideración ética 7-1 establecía que el abogado debía promover "celosamente" los intereses y objetivos de su cliente. Las Model Rules que vinieron a reemplazarlo quitaron de la normativa cualquier referencia al "celo" en la defensa $a^{15}$. La regla 1.3 señala que el abogado debe promover los intereses de su cliente con "diligencia" y "prontitud". Sin embargo, en los comentarios a esta regla la "celosa defensa" vuelve a hacer su aparición: el comentario

patrimonio exclusivo de Estados Unidos. En la mayor parte de las culturales legales de Latinoamérica se observa un patrón semejante.

${ }^{15}$ Algunos sostienen que la exhortación a la celosa defensa de los intereses del cliente fue quitada porque se pensaba que promovía que los abogados se comportaran de modo contrario a la ética. 
1 establece que el abogado debe actuar: “...con celo a la hora de abogar en beneficio de su cliente..."

Consideraciones semejantes se encuentran en el Código de Ética para el ejercicio de la profesión de abogado en la Capital Federal de Argentina. El art. 19.a señala que el abogado debe: “... atender los intereses confiados con celo, saber y dedicación...”. Una exigencia casi idéntica se encuentra en el Código de Ética y Disciplina de La Pampa, que en su art. 1 establece en relación con los abogados “... que la esencia de su deber profesional es consagrarse enteramente a los intereses de su cliente, y poner en la defensa de los derechos del mismo su celo, saber y habilidad...”. La ley de Ejercicio de la Profesión de Abogado de la provincia de Córdoba, no hace referencia en su texto al "celo" en defensa de los intereses del cliente, pero se interpreta en este sentido a la regla ética contenida en el art. 21 inc. 10 que caracteriza como una falta "abandonar o descuidar inexcusablemente la defensa...".

El Código de Ética Profesional del Colegio de Abogados de Chile, por su parte, estipula en su art. 3 que: "El abogado debe obrar siempre en el mejor interés de su cliente y anteponer dicho interés al de cualquier otra persona, incluyendo al suyo propio”. El Código de Ética de los Abogados para Perú establece en su art. 27 que “...es deber del abogado defender el interés del cliente de manera diligente y con un elevado estándar de competencia profesional". El Código de Ética del Ilustre y Nacional Colegio de Abogados de México, señala en su preámbulo que en la relación que lo vincula con su cliente, el abogado “... tiene la obligación de defender sus derechos y libertades; es, por lo tanto, el asesor $y$ defensor de su cliente... ". En el mismo sentido se expresa el art. 2.7. 1 cuando declara que "...el Abogado tiene la obligación de defender lo mejor posible los intereses de su cliente, incluso en contraposición a los suyos propios, a los de un colega o a aquellos de la profesión en general". El art. 2.7.2 hace explícita la adhesión del Código al principio de

${ }^{16}$ El comentario continúa señalando que la regla no establece que el abogado no está "obligado" al uso de tácticas que sean ofensivas, o "impide" tratar a las personas con cortesía y respeto. Esto muestra el alcance de la "celosa defensa". De acuerdo con el comentario parece que el uso de tácticas ofensivas y el trato descortés e irrespetuoso es "permisible". Como señalan Lerman - SchraG, cit. (n. 9), p. 292, si lo que se quería era limitar el "celo" en la defensa, “...hubiese tenido más sentido que el comentario prohibiese tácticas ofensivas y requiriese un trato respetuoso”. 
"celosa defensa" dentro de los límites de la ley, al señalar que “...el abogado podrá defender a su cliente, aún a sabiendas de que es culpable, y procurar obtener una sentencia de inocencia, siempre y cuando no recurra a ningún medio ilícito". El Código de Ética Profesional de la Barra Mexicana, por su parte, señala en su artículo 1 que "la esencia de su deber profesional es defender diligentemente y con estricto apego a las normas morales, los derechos de su cliente". El art. 7 inciso 2 del mismo cuerpo normativo sostiene que la misión del abogado es la de "... defender a su cliente en el marco de la ley de la forma que considere más apropiada”. El art. 11 inciso 2 establece que el abogado "...no debe anteponer su propio interés al de su cliente".

La lealtad que el abogado debe a los intereses públicos, también ha tenido una profusa recepción en las reglas que regulan el desempeño profesional. El preámbulo de las Model Rules of Professional Conduct de la ABA señala que el abogado es un "...funcionario del sistema jurídico... ”. La regla 1.2, por su parte, señala que el abogado no puede aconsejar o asistir a su cliente la realización de conductas criminales o fraudulentas. El comentario 10, a su vez, aclara que el abogado no debe ayudar a que el cliente, por ejemplo, elabore documentos falsos ni debe utilizarlos. Tampoco debe ayudarlo brindándole información acerca de la manera en que el fraude podría ser encubierto. Cuando el abogado toma conocimiento de que el objeto en el que estaba representando o asesorando a su cliente es ilegal, entonces debe renunciar a la representación y cesar el asesoramiento ${ }^{17}$.

El Código de Ética para el ejercicio de la profesión de Abogado en la Capital Federal establece en su art. 6 que: “...es misión esencial de la abogacía el afianzar la justicia..." y en el 7 que "...es deber del abogado preservar y profundizar el Estado de Derecho... ”. El art. 1 del Código de Ética y Disciplina de La Pampa, señala que el abogado:

${ }^{17}$ En algunas ocasiones la lealtad del abogado al sistema le exige más que meramente renunciar a la representación o evitar brindar asesoramiento. Así, la regla 1.6.b establece que: "El abogado puede revelar información relacionada con la representación de un cliente hasta el punto en que el abogado razonablemente crea que esto es necesario: (2) para evitar que el cliente cometa un delito o estafa, que es razonablemnte cierto que provocara un daño sustancial a los intereses financieros o la propiedad de otro y en cuya prosecución el cliente haya utilizado o esté utilizando los servicios del abogado; (3) para evitar, mitigar o rectificar un daño sustancial a los intereses financieros o la propiedad de otro y en cuya prosecución el cliente haya utilizado o esté utilizando los servicios del abogado". 
"...es un servidor de la justicia y un colaborador de su administración..." La normativa que regula el ejercicio profesional en Córdoba, por su parte, establece en el art. 19 inc. 1 que es deber del abogado “... prestar su asistencia profesional como colaborador del Juez y en servicio de la Justicia”. El Código de Ética Profesional chileno en su art. 2 señala que "... las actuaciones del abogado deben promover, y en caso alguno afectar (...) la correcta y eficaz administración de justicia, y la vigencia del estado de derecho". El Código de Ética del Abogado de Perú dice en su art. 2 que la profesión de abogado "...cumple una función social al servicio del Derecho y la Justicia...” y el art. 3 agrega que "... la abogacía tiene por fin la defensa de los derechos de las personas y la consolidación del Estado de Derecho, la justicia y el orden social". El Código de Ética Profesional de la barra mexicana dice en su preámbulo que "el abogado ha de tener presente que es un servidor del derecho y un coadyuvante de la justicia...”. El Código de Ética del Ilustre y Nacional Colegio de Abogados de México, por su parte, señala en su preámbulo que "...en una sociedad fundada en el respeto a la Justicia, el Abogado tiene un papel fundamental. Su misión no se limita a ejecutar fielmente un mandato en el marco del Derecho. En un Estado de Derecho, el Abogado es indispensable para lograr el respeto y cumplimiento de la Justicia".

Algunos Códigos de Ética, como el del Ilustre y Nacional Colegio de Abogados de México, reconocen el carácter potencialmente conflictivo de las diferentes lealtades que confluyen en el rol de abogado y, en consecuencia, de los diferentes deberes que sobre él pesan. En su preámbulo, haciendo explícita esta tensión, señala que la misión del abogado "...le impone deberes y obligaciones múltiples, algunas veces con apariencia contradictoria, con respecto: A si mismo. Al cliente. A los tribunales y otras autoridades ante las cuales el Abogado asiste o representa al cliente. A su profesión en general y a cada colega en particular. A la sociedad, para la cual una profesión liberal e independiente, regida por el respeto a las reglas que se ha impuesto a si misma, es un medio esencial de proteger los derechos del hombre frente al estado y a los otros poderes... ". No obstante, lo reconozcan en su normativa o no, el potencial conflicto entre lealtades se encuentra presente en todos los ordenamientos regulativos.

Adicionalmente, para garantizar la lealtad en los intereses del abogado en relación con el cliente, los códigos de ética profesional 
han desarrollado un entramado de normas que intentan identificar y evitar los conflictos de intereses. La focalización sobre este tipo de problema es una característica generalizada de las regulaciones de ética profesional. A modo de ejemplo, puede señalarse el dato sumamente revelador de que un tercio de las páginas de las Model Rules de la ABA y sus comentarios, están dedicadas al conflicto de intereses. La mayor parte de las consultas que reciben los abogados especialistas en ética legal se refieren a problemas de conflicto de intereses ${ }^{18}$.

Finalmente, la esperanza de que la justicia sea alcanzada y el interés público promovido, por la celosa defensa de los intereses privados de los clientes, también se encuentra presente en los cuerpos normativos que regulan el ejercicio profesional. En algunos casos, como en el caso de las Model Rules of Professional Conduct, la presencia es patente. El preámbulo expresamente declara que: “...cuando la parte contraria está bien representada, el abogado puede ser un celoso defensor de los intereses de su cliente y al mismo tiempo dar por sentado que se ha hecho justicia". En otros cuerpos normativos la presencia es implícita y se encuentra enraizada en el modo en que las normas de "celosa defensa" son interpretadas y justificadas.

\section{LIBERTAD COMO NO-INTERFERENCIA}

En lo que sigue intentaré mostrar que esta manera de vincular las diferentes lealtades que atraviesan el rol de abogado, y el modo al que conduce de configurar el rol, se asienta en un modo peculiar de concebir a la libertad como no-interferencia. Aunque han existido diversos autores que han explorado el concepto de libertad negativa ${ }^{19}$, del cual la libertad como no-interferencia es una variante, el lugar paradigmático para abordar su análisis es la obra de Isaiah Berlin. Su elección no sólo se justifica en la influencia que ha ejercido en el discurso público y en la articulación de los debates académicos posteriores, sino también por el modo en que vincula a la libertad negativa con un modo de concebir la política y con una manera de resistir al totalitarismo. Pienso que todos estos temas, juntos

\footnotetext{
${ }^{18}$ Lerman - Shrag, cit. (n. 9), p. 356.

${ }^{19}$ HAYEK, Friedrich, Law, Liberty and Legislation (Chicago, University of Chicago Press, 1973), I; Oppenheim, Félix, Dimensions of Freedom: An Analysis (New York, St. Martin's Press, 1961); Steiner, Hillel, An Essay on Rights (Oxford, Blackwell,
} 1994). 
con la manera de concebir la libertad al que son anexos, se encuentran presentes en el discurso que ha contribuido a configurar el actual rol profesional del abogado.

De acuerdo con Berlin la libertad como no-interferencia, en tanto libertad negativa, tiene que ver con la pregunta: “...¿Cuál es el área dentro de la cual el sujeto -la persona o un grupo de personas- está o debería ser dejado hacer o ser lo que quiera, sin la interferencia de otras personas?... "20. Con esta caracterización en mente, Berlin presenta a la libertad como no-interferencia como una variante corregida de la concepción de libertad como no-frustración de Hobbes.

Para Hobbes la libertad de elección solo exige que no existan obstáculos -naturales o fruto de la interferencia deliberada de otro agente- para poder llevar adelante la opción preferida por el agente en cuestión ${ }^{21}$. Berlin discrepa en dos sentidos. En primer lugar, sostiene que sólo la interferencia fruto de la acción deliberada de un agente cuenta como una transgresión a la libertad ${ }^{22}$. En segundo lugar, para Berlin la libertad posee un carácter modal. Para que alguien sea libre no deben existir obstrucciones deliberadas -esto es interferencias- a la opción preferida en el mundo actual y en los mundos posibles cercanos donde las preferencias del agente son diferentes y hasta opuestas. De acuerdo con la reconstrucción de la posición de Berlin ofrecida por Pettit: “...tú eres libre en el mundo actual no solo en virtud de que este es un mundo sin interferencia sino también en virtud de que es un mundo donde ciertas características implican que tú no sufrirías interferencia aun si eligieses de un modo diferente al que de hecho hiciste"23.

El argumento de Berlin en contra de la libertad como no-frustración hace hincapié en que parece contraintuitivo afirmar que alguien puede volverse libre sólo por extinguir los deseos que tiene de realizar aquellos cursos de acción que se encuentran bloqueados por la existencia de interferencias. Si ser libre sólo consistiese en poder hacer cualquier cosa que

${ }^{20}$ Berlin, Isaiah, Two Concepts of Liberty, en Liberty (Oxford, Oxford University Press, 2002), p. 169.

${ }^{21}$ Pettit, cit. (n. 2), p. 697.

${ }^{22}$ Berlin, cit. (n. 20), p. 169. Según el autor: “...careces de libertad política o libertad sólo sit e encuentras impedido de alcanzar un objetivo por algún ser humano ...”; Este es un punto con el que Pettit acuerda. Para éste: “...los límites naturales reducen el ámbito sobre el cual tú puedes disfrutar tu libertad de la voluntad de otros y hasta pueden ser instrumentales en hacerte vulnerable a su voluntad - y por lo tanto estos límites exigirían ser remediados. Pero...tales límites no te privan por si mismos de tu libertad; ellos no te hacen alguien carente de libertad de la misma manera en que otros agentes sí pueden hacerlo ..."; Ретtiт, cit. (n. 2), p. 694.

${ }^{23}$ PetTit, cit. (n. 2), p. 701. 
uno desee sin sufrir la interferencia de otros, tal como sostiene la libertad como no-frustración, un modo de alcanzar la libertad sería eliminar todos aquellos deseos que no pueden ser satisfechos debido a la interferencia de terceros. Si lo contrario a la libertad es la frustración, uno puede evitar la frustración y alcanzar la libertad meramente por acomodar los propios deseos en lugar de eliminar las interferencias ${ }^{24}$. Como esta conclusión parece absurda, ya que no diríamos que alguien que acomoda sus deseos a aquel que interfiere es alguien libre sino más bien alguien resignado, la libertad como no-frustración debe ser falsa.

A pesar de las diferencias que existen entre la libertad como no-frustración de Hobbes y la libertad como no-interferencia de Berlin, ambas concepciones acuerdan acerca del carácter restrictivo de la libertad que poseen las normas jurídicas. Estos dos modos de concebir a la libertad ven a los límites jurídicos como un límite a la autonomía individual. La razón es simple, dado el carácter coercitivo del derecho todas las normas jurídicas en mayor o menor medida interfieren con la realización de ciertas conductas individuales. El derecho es siempre una restricción, o una "cadena”, “... aun si te protege de estar atado por cadenas que son más pesadas que las de la ley, tales como las del despotismo arbitrario y el caos..."25.

El carácter coercitivo del derecho le viene dado por el hecho de que los sistemas jurídicos prescriben estados de cosas o cursos de acción y lo hacen con independencia de cuáles sean las conductas o estados de cosas que sean deseados o preferidos por aquellos a quienes se aplican. Así, por ejemplo, haber nacido en un esquema institucional que contenga el instituto de la herencia de bienes impone sobre todos aquellos a quienes se aplica un patrón desigual de distribución de la riqueza que no existiría si tal instituto no existiese o fuese modificado. Los ciudadanos a quienes se aplican esas normas jurídicas soportarán ese estado de cosas -la distribución desigual de recursos- sea cuales sean sus deseos al respecto. Por otro lado, haber nacido en un sistema jurídico que reconoce la propiedad privada y la grava con impuestos, impone sobre todos sus destinatarios un curso de acción. Sea cuales sean sus deseos serán coercionados a pagar sus cargas tributarias. Que las normas jurídicas produzcan estos efectos sobre la situación en la que viven o las acciones que realizan los individuos a quienes se aplican, y que estos efectos se produzcan con independencia de cuáles sean sus deseos o preferencias, indefectiblemente debe tener costos en términos de libertad si se entiende que alguien es libre cuando no existen obstáculos para la satisfacción de sus intereses. Así, para seguir

\footnotetext{
${ }^{24}$ Pettit, cit. (n. 2), p. 699.

${ }^{25}$ BerLin, cit. (n. 20), p. 170.
} 
con los dos ejemplos brindados, aquellos ciudadanos que desean vivir en una sociedad más equitativa o desean no dar parte de su riqueza al Estado, han sufrido una pérdida de libertad -entendida como no-interferencia-a manos del sistema jurídico. Las normas jurídicas representan obstáculos para la satisfacción de sus deseos.

Una consecuencia relevante de concebir de este modo a la libertad es que sin importar cuál sea la forma de gobierno, o el procedimiento de creación y aplicación de las normas jurídicas, o su carácter legítimo o ilegítimo, toda norma jurídica interfiere con la libertad individual. En este sentido, la libertad como no-interferencia no toma distancia de las palabras de Hobbes en relación con la inscripción "Libertas" en la torre de la ciudad de Luca: "nadie puede inferir, por lo tanto, que un hombre tiene allí más Libertad, o más Inmunidad de los servicios que la Comunidad Política le puede exigir, que la que tendría en Constantinopla. Sea una Comunidad Política Monárquica, o Popular, la Libertad sigue siendo la misma"26.

\section{LIBERTAD COMO NO-INTERFERENCIA Y ROL PROFESIONAL}

Si se emplea esta idea de libertad como no-interferencia para dar contenido a las dos exigencias de lealtad que definen el rol de abogado -la referida a los intereses del cliente y la referida a los intereses colectivos o públicos- aparece una imagen del ejercicio profesional y del rol de abogado que contiene los cinco elementos antes señalados: el abogado debe llevar adelante una "celosa defensa" de los intereses del cliente dentro de los límites de la ley que es equivalente a la defensa de su libertad, cumple meramente una tarea de asistencia técnica, al defender los intereses privados contribuye a la realización de los intereses públicos o a la realización de la justicia, toda regulación al ejercicio profesional es vista con recelo, y la ética profesional es percibida como una "ética de principios o reglas".

En primer lugar, una vez que se concibe a la libertad como no-interferencia, la lealtad que el abogado debe a los intereses del cliente determina que éste pase a ser visto como un "protector de su libertad". Caracterizar la protección o promoción de los intereses o deseos del cliente en términos de libertad es algo sencillo cuando la libertad es interpretada como la posibilidad de llevar adelante sin interferencias los cursos de acción que coinciden con los deseos o preferencias que uno tiene o podría tener. El abogado, al intentar que el cliente pueda actuar tal y como lo desea, o al intentar minimizar las interferencias que existen sobre sus conductas, se transforma en un garante de su libertad individual.

${ }^{26}$ Hobbes, Thomas, Leviathan (New York, Touchstone, 1997), p. 132. 
La lealtad a los intereses públicos que vuelve al abogado un "auxiliar de la justicia”, por su parte, es traducida en mero "respeto por la legalidad". Entender el aspecto público que posee el rol de abogado en términos de legalidad -haciendo que la idea de "justicia” no tenga vinculación alguna con la legitimidad política o moral- es natural si se sostiene que los sistemas jurídicos legítimos o ilegítimos son igualmente costosos en términos de libertad individual. Si el derecho es siempre una "cadena”, las diferencias entre las leyes legítimas y las ilegítimas se diluye, y queda abierto el camino para que la lealtad a los intereses públicos sea interpretada en términos de respeto a la mera legalidad.

Una vez que las lealtades que confluyen en el rol de abogado son interpretadas utilizando la concepción de libertad como no-interferencia, aparece una manera natural de combinarlas. El abogado debe proteger la libertad de su cliente, promoviendo sus intereses, utilizando todo los medios legales a su alcance. El límite a la defensa es la mera legalidad. En los ordenamientos donde no existen referencias a la justicia sino a la ley, esta solución aparece como la más plausible. Este es el caso, por ejemplo, de las Model Rules of Professional Conduct de la ABA. Donde se dice que el abogado es un oficial del sistema legal, y debe ejercitar la defensa dentro de los límites de la ley.

La misma interpretación legalista queda abierta para aquellos ordenamientos de la conducta profesional que hacen explícita referencia a la justicia o el Estado de Derecho. Las disposiciones que establecen que el abogado es un "auxiliar de la justicia" deben ser interpretadas como haciendo referencia al "sistema judicial". Una vez hecho esto el abogado ya no colabora para descubrir la solución justa, sino que colabora con el funcionamiento correcto del sistema de justicia. Aunque la norma hace referencia a la justicia, ésta pasa a ser interpretada de un modo legalista y el abogado se transforma en un colaborador de la "administración de justicia", esto es del Poder Judicial. La misma maniobra interpretativa debe hacerse con las referencias al Estado de Derecho, privándolo de toda vinculación con la legitimidad política, reduciéndolo al mero respeto por la ley.

El modo de combinar la lealtad privada y pública que aparece cuando se utiliza para interpretarlas a la libertad como no-interferencia es uno que conduce de manera directa a la idea de "celosa defensa dentro de los límites de la ley”. La lealtad pública, hemos visto, determina que el abogado no deba transgredir la ley ni contribuir a que su cliente la transgreda. Sin embargo, los costos que toda ley tiene en términos de libertad individual determinan que el abogado deba extremar los recursos argumentativos e interpretativos para disminuir el impacto que ésta pueda tener en la satisfacción de los intereses de su cliente. El abogado debe promover o 
defender los intereses de su cliente brindando la interpretación de la ley que sea más favorable a ellos. Si brinda una interpretación plausible de la norma jurídica que no interfiere con los intereses de su cliente, entonces ha satisfecho tanto las exigencias de lealtad pública como privada.

Existe una asimetría en la manera en que ambas lealtades se articulan en la idea de "celosa defensa dentro de los límites de la ley". No es tarea del abogado preguntarse cuáles son los fines que persigue la norma jurídica ni, menos aún, intentar promoverlos. La tarea de promover los intereses colectivos corresponde al legislador, no al abogado. Son los legisladores quienes deben debatir qué fines colectivos son dignos de ser perseguidos y cuáles son los mejores medios legales para alcanzarlos. La razón de esta desconexión entre la tarea del abogado y la promoción de los fines de las normas jurídicas tiene que ver con la independencia conceptual que existe entre la libertad como no-interferencia y la libertad como auto-gobierno o auto-control.

Para quienes conciben a la libertad como no-interferencia la libertad corporizada en la actividad legislativa -si existe alguna- es una especie de libertad positiva relacionada con la pregunta “... ¿Qué o quién es la fuente de control o de interferencia que puede hacer que alguien haga o sea esto en lugar de aquello?..."27. Si se trata de un parlamento democrático, entonces todos los ciudadanos a través de sus representantes son la fuente que determina los fines que persigue el derecho y controlan su poder de interferencia. Esto, sin embargo, no aminora la amenaza que las normas jurídicas ejercen sobre la libertad negativa como no-interferencia de los ciudadanos, de la cual los abogados son garantes.

Que la interferencia generada por las normas jurídicas sea producto de la libertad positiva de la comunidad política -esto es, que sea un ejercicio de auto-gobierno colectivo- no dice nada todavía sobre el grado de libertad negativa como no interferencia de la que gozan los ciudadanos a los que estas normas se aplican. La independencia conceptual, en última instancia, se funda en que ambos conceptos de libertad responden a dos preguntas diferentes. En palabras de Berlin “...La respuesta a la pregunta: ‘¿Quién me gobierna?' es lógicamente diferente de la pregunta '¿Qué tanto el gobierno me interfiere?’. En última instancia, en esta diferencia consiste el gran contraste entre los dos conceptos de libertad negativa y positiva..." ${ }^{28}$.

Berlin enfatiza la independencia entre ambos tipos de libertad de modo provocativo mostrando cómo la libertad como no-interferencia puede ser promovida por un gobierno autocrácito. La libertad como no-interferencia

\footnotetext{
${ }^{27}$ Berlin, cit. (n. 20), p. 169.

${ }^{28}$ Berlin, cit. (n. 20), p. 178.
} 
"...no es incompatible con algunos tipos de autocracia, o de cualquier modo con la ausencia de auto-gobierno. La libertad en este sentido se refiere principalmente al área de control, no a su fuente (...). El déspota que deja a sus súbditos una amplia área de libertad puede ser injusto, o promover las más salvajes desigualdades, preocuparse poco por el orden, o la virtud, o el conocimiento..." ${ }^{29}$. Sin embargo, que el régimen autocrático sea injusto o malo en otros aspectos, no dice nada sobre el hecho de si promueve o no la libertad como no-interferencia. De allí que la libertad como no-interferencia “....no está de ningún modo lógicamente conectada con la democracia o el auto-gobierno" 30 .

Esta independencia conceptual entre la libertad colectiva como autogobierno, aun si éste es ejercitado a través de medios democráticos, y la libertad individual como no-interferencia, desvincula la tarea del abogado como promotor de los intereses de su cliente y protector de su libertad de la promoción de los intereses colectivos vinculados con el auto-gobierno y corporizados en el ordenamiento jurídico. No es tarea del abogado intentar promover los fines que la comunidad política intenta alcanzar a través de la imposición coercitiva de las normas jurídicas. Aun si estos fines colectivos han sido determinados de manera democrática, nada garantiza que su promoción sea congruente con la protección de la libertad individual. El abogado, en tanto defensor de la libertad del cliente, no debe preguntarse por los fines de las normas jurídicas, aun si estos son frutos del ejercicio del auto-gobierno, ni preocuparse por si estos son o no promovidos por la manera en que ejerce su profesión defendiendo los intereses de su cliente.

Como es evidente, existe aquí una tensión entre el apego irrestricto a la ley que se sigue de la interpretación legalista de la lealtad pública y la despreocupación a la hora de ejercitar su rol por los fines que persigue la norma jurídica. Después de todo si la ley va a ser respetada debe serlo, entre otras cosas, por su carácter valioso; y si la ley posee este carácter parece que necesariamente también deben ser valiosos los fines colectivos que persigue. Ahora bien si los fines colectivos corporizados en las normas jurídicas se presumen valiosos -si uno adopta la interpretación legalista de la lealtad pública- ¿cómo puede sostenerse de manera consistente que el abogado no debe intentar promoverlos a la hora de ejercitar su profesión?

Dos consideraciones son necesarias aquí. La primera, se refiere a un modo de concebir el auto-gobierno colectivo ejercitado a través de la actividad política, y el rol de las normas jurídicas. Si la libertad es concebida como no-interferencia, no sólo es posible que los gobiernos autocráticos

\footnotetext{
${ }^{29}$ Berlin, cit. (n. 20), p. 176.

${ }^{30}$ Berlin, cit. (n. 20), p. 176.
} 
la promuevan, sino que también es igualmente posible que los gobiernos democráticos la vulneren. De acuerdo con Berlin, quienes conciben a la libertad como auto-control individual, y sostienen que ser libre consiste en que las partes más valiosas de uno mismo se impongan sobre las menos valiosas, tarde o temprano pasan a aplicar este concepto positivo de libertad como auto-gobierno al ámbito político ${ }^{31}$. Al hacer esta transición del auto-gobierno individual al colectivo, terminan justificando que los fines determinados por la porción más valiosa de la comunidad política -sea que esta se conciba de modo aristocrático como la más educada, o de modo democrático como la más numerosa- sean impuestos de manera coercitiva sobre todos, incluso sobre aquellos que no los comparten. De este modo, concluye Berlin: "...lo que había comenzado como una doctrina de la libertad se transformó en una doctrina de la autoridad y, a veces, de la opresión, y resultó el arma favorita del despotismo..."”32.

Como no podría ser de otro modo, esta desconfianza frente al autogobierno colectivo se traslada al modo de concebir la actividad política. Si el primero es concebido como libertad positiva, esto es como "libertad para", es natural concebir a la segunda como un intento de imponer una determinada forma de vida. Si se entiende a la libertad de modo positivo, y se le agrega un carácter colectivo, entonces la política se transforma en un modo de ejercitar "la libertad para imponer una forma de vivir". La política, entendida con el trasfondo de la libertad positiva, adopta tintes perfeccionistas potencialmente peligrosos para la libertad como no-interferencia de los ciudadanos.

Este modo de concebir al auto-gobierno y a la política contribuye a reforzar la idea de que el abogado -en tanto protector de la libertad

${ }^{31}$ BerLin, cit. (n. 20), p. 191.

${ }^{32}$ BerLin, cit. (n. 20), p. 37. Es necesario aclarar que el potencial justificatorio del despotismo del concepto de libertad positiva entendida como auto-gobierno colectivo no es exclusivo de éste. El propio Berlin se encarga de señalar que justificar ese tipo de gobiernos opresivos “...podría del mismo modo haber sido el destino de la doctrina de la libertad negativa. Entre los dualistas que distinguían los dos sujetos, algunos -en particular los teólogos judíos y cristianos, pero también los metafísicos idealistas del siglo diecinueve- hablan de la necesidad de liberar el sujeto "elevado" o "ideal" de los obstáculos que tiene en su camino, tales como la interferencia de, "el estar esclavizado a", el "sujeto más bajo"; y algunos veían a esta entidad degradada como encarnada en las instituciones que sirven a pasiones irracionales o depravadas u otras fuerzas del mal propensas a obstruir el desarrollo adecuado del sujeto "verdadero" o "elevado", o "la mejor versión de mí mismo". La historia de las doctrinas políticas podría (como sucedió con alguna de las sectas Protestantes) haber tomado esta forma "negativa". El punto de Berlin es que, aunque esta posibilidad existía, no ha sido el camino que tomó el pensamiento político en occidente. 
individual de su cliente- no debe preguntarse ni intentar promover los fines colectivos que el gobierno puede haber tenido a la hora de dictar las normas jurídicas. Mientras la independencia conceptual entre ambos tipos de libertad hace que esto sea posible, poner de manifiesto el potencial carácter perfeccionista y autoritario del auto-gobierno colectivo hace que tal actitud del abogado sea exigible. Si el abogado va a ser el defensor de la libertad de su cliente, y los fines que persigue la comunidad política en ejercicio del auto-gobierno son una potencial amenaza para la libertad individual, es necesario que el abogado no interprete los límites jurídicos teniendo en mente esos fines.

El abogado no debe preocuparse por promover los fines colectivos corporizados en las normas jurídicas -aun si estos son frutos de un ejercicio democrático de libertad positiva- porque para quien valora la libertad como no-interferencia la libertad positiva representa una amenaza potencial. Ahora bien, si esto es así, si los "límites de la ley" son producto del ejercicio del poder político y éste siempre tiene un potencial tiránico, ¿cómo puede justificarse que el abogado deba ajustarse estrictamente a lo que marca la ley a la hora de defender la libertad de su cliente? Parece que el concebir a la libertad como no interferencia no sólo conduce a que el abogado no deba interpretar a la ley teniendo en mente los fines colectivos que promueve, sino a la idea mucho más extrema de que el abogado no debe ajustarse a la ley.

Si las normas jurídicas pudiesen promover sólo los fines establecidos a través del ejercicio de la libertad positiva para imponer sobre todos ciertos ideales colectivos, ciertamente esta sería la conclusión. Sin embargo, para quienes valoran la libertad negativa todavía queda una alternativa. Las normas jurídicas persiguen fines valiosos cuando funcionan como barreras que protegen un ámbito donde los individuos pueden satisfacer sus deseos sin interferencias. Dado el potencial tiránico que posee el Estado cuando intenta imponer fines colectivos -aun si estos son producto del auto-gobierno- si las normas jurídicas van a ser consideradas legítimas y generando algún deber de obediencia, entonces deben ser interpretadas como protecciones frente al poder coercitivo del Estado. Hasta los derechos jurídicos que podrían estar más vinculados con el auto-gobierno, como los derechos políticos, deben ser interpretados de este modo. No son derechos cuya finalidad es permitir que los ciudadanos participen en la conducción de los asuntos colectivos, sino como "...barreras contra la intervención del Estado..."33.

Esta última consideración explica por qué el abogado, en tanto defensor de la libertad de su cliente, debe, por un lado, apegarse estrictamente a

${ }^{33}$ BerLin, cit. (n. 20), p. 171. 
lo que prescriben las normas jurídicas y, por el otro, debe interpretarlas de manera que no interfieran con los deseos que aquel posee. Las normas jurídicas son las últimas barreras de protección frente a la interferencia estatal. Si el abogado no se apega a ellas, contribuye a socavarlas dejando a su cliente y al resto de los ciudadanos a merced del Estado. Sin embargo, si las normas jurídicas valiosas desde el punto de la libertad como no-interferencia son aquellas que tienen por objeto poner freno a la interferencia estatal, el abogado debe interpretar todo el entramado jurídico presuponiendo que éste es el fin que persigue, sea cuales sean los fines específicos que el legislador tuvo en mente a la hora de dictarlas. Si las normas jurídicas tienen por único fin legítimo limitar la interferencia estatal, interpretarlas de modo de minimizar su poder de interferencia sobre los deseos del cliente, no entra en conflicto con considerar valioso apegarse a ellas en el ejercicio del rol profesional.

La protección de la libertad como no-interferencia de todos los ciudadanos se alcanza a través de una especie de división del trabajo moral. Cada abogado sólo debe defender celosamente los intereses de su cliente "dentro de los límites de la ley". El sistema adversarial articula esta división del trabajo y permite, combinado con la idea de libertad como no-interferencia, alcanzar la aspiración expresada en el preámbulo de las Model Rules of Professional Conduct: la celosa defensa de partes opuestas permite que la justicia sea satisfecha. Una vez que la libertad es concebida como mera no-interferencia el proceso judicial se transforma en un juego de suma cero en el que lo que una parte gana en términos de libertad es equivalente a lo que la otra pierde. En un contexto semejante la justicia no puede medirse teniendo en cuenta el resultado -que siempre tendrá el mismo valor en términos de libertad como no-interferencia- sino sólo teniendo en cuenta la equidad del procedimiento. De allí la idea de que si ambas partes cuentan con igualdad de armas para intentar satisfacer sus intereses a través del proceso judicial, y ambas cuentan con una celosa defensa por parte de su abogado, entonces la justicia ha sido satisfecha.

La idea de "celosa defensa dentro de los límites de la ley", entendida con el trasfondo de la libertad como no-interferencia, conduce a un rasgo adicional del rol de abogado. Para lograr esta celosa defensa lo que se espera del abogado es sólo conocimiento técnico. El rol del abogado es principalmente instrumental, en el sentido que brinda asistencia técnica para que el cliente pueda actuar de acuerdo con sus intereses. Los fines que el abogado persigue en el ejercicio profesional son los del cliente y no es su tarea moldearlos o evaluarlos. Si la libertad es entendida como no-interferencia y el abogado es concebido como un celoso guardián de la libertad, es obvio que entre sus funciones no debe incluirse la de alterar los 
deseos o preferencias de su cliente. El abogado que disminuye la interferencia de la que es objeto su cliente, simplemente haciendo que éste altere sus fines o deseos, no se ha comportado como un promotor de su libertad.

Justamente éste último es el punto de crítica que Berlin formula a la libertad como no-frustración Hobbesiana. Para que la libertad del cliente sea respetada, el abogado debe encargarse de extinguir las obstrucciones deliberadas -incluidas las corporizadas en las normas jurídicas de carácter coercitivo- no sólo en relación con las conductas que se propone llevar adelante dado los deseos que de hecho tiene, sino también en relación con aquellas conductas que acometería si tuviese deseos diferentes u opuestos. De manera que la estrategia de promover la libertad del cliente haciendo que desaparezca la interferencia del sistema jurídico sobre su conducta, al provocar la alteración de sus deseos para que ahora sean congruentes con la norma jurídica, no es una que se encuentre disponible para el abogado. Por supuesto, cuando los deseos del cliente son ilegales el abogado no puede prestar su asistencia para promoverlos debido a las exigencias de lealtad pública que pesan sobre él. Pero aun en este caso, intentar alterar los deseos del cliente no es una exigencia que se siga de la lealtad privada que le debe ya que esta alteración no aumenta en modo alguno la libertad como no-interferencia de la que goza.

Cuando los deseos del cliente son frontalmente contrarios a derecho, esto es cuando el abogado no encuentra ninguna interpretación plausible de las normas jurídicas que no se contraponga a los deseos del cliente, el abogado no debe prestar su asistencia técnica para promoverlos. No es la tarea del abogado juzgar los deseos del cliente ni intentar alterarlos. Mientras mayor sea la dependencia del abogado en relación con los deseos del cliente, mayor garantía existe de que aquél actúa como una barrera de protección de la libertad como no-interferencia de éste.

Con todo, no debe exagerarse el rol que la adopción de la libertad como no-interferencia juega en la tendencia de los abogados a no oponerse a los deseos del cliente. Otros elementos coyunturales pueden contribuir a que esta situación se consolide. Entre ellos ocupa un lugar destacado el carácter altamente competitivo que ha adquirido la profesión dado el creciente número de abogados. Los clientes saben que con un número abultado de abogados, si uno se resiste a promover sus intereses, es muy probable que encuentren a otro que lo haga. Esto genera una enorme presión sobre los abogados fundada en el temor de perder sus clientes si deciden no satisfacer los intereses que poseen, aun si piensan que estos son de dudosa legalidad ${ }^{34}$.

\footnotetext{
${ }^{34}$ Rhode, Deborah, Ethics in Practice, en Ella misma (ed.), Ethics in Practice: Lawyer's Role, Responsibility and Regulation (Oxford, Oxford University Press, 2000),
} p. 4. 
Concebir a la libertad como no-interferencia, a la política y a la injerencia estatal como potencialmente peligrosa, y a las normas jurídicas como barreras frente a estas injerencias, conduce también a un modo de entender los estándares que regulan la conducta profesional. Adiestrados en interpretar a las normas legales de manera restrictiva, intentando minimizar su poder de interferencia sobre la conducta del cliente, no es de extrañar que los abogados entiendan de este mismo modo los estándares normativos que regulan su propia conducta. Un abogado bien adiestrado en temas de ética profesional es aquel que conoce a la perfección las exigencias de los códigos de ética, y se apega escrupulosamente a su letra, a la vez que es hábil para encontrar interpretaciones que sin vulnerar la literalidad de las normas se desentiende por completo de su espíritu y finalidad.

La "infraestructura ética" que han desarrollado los grandes estudios jurídicos, construyendo departamentos poblados por especialistas en ética profesional, ha estado focalizada en evitar incurrir en responsabilidad profesional por prácticas contrarias a los estándares éticos ${ }^{35}$. Estos departamentos actúan en relación con el resto de los abogados a los que aconsejan, del mismo modo y con las mismas herramientas interpretativas que éstos actúan con sus clientes. Así como el abogado intenta minimizar el poder de interferencia de las normas jurídicas sobre las conductas del cliente, los departamentos de ética profesional intentan minimizar la interferencia de los estándares éticos sobre la conducta de los abogados, evitando de este modo su incursión en causales de responsabilidad.

La idea recelosa de la política y la injerencia del Estado, asociada con la libertad como no-interferencia, brinda razones adicionales para la resistencia de los abogados frente a cualquier intento estatal de regular la profesión. Este recelo se emparenta con el ideal de auto-regulación a través de los colegios profesionales. En este paradigma el pincipal rol de los Colegios de Abogados pasa a ser el de resistir cualquier interferencia del Estado en el ejercicio profesional. El ideal de que la profesión se auto-regule minimizando las regulaciones de origen estatal pasa a ser justificado como una manera de garantizar la independencia de los abogados frente al Estado. En este sentido son interpretadas declaraciones como la del preámbulo

${ }^{35}$ Chambliss, Elizabeth - Wilkinks, David, Promoting Ethical Infrastructure in Large Law Firms: A Call for Research and Reporting, en Hofstra Law Review 30 (2002), 3, p. 716; los autores estuvieron entre los primeros en advertir la necesidad de esta "infraestructura ética" así como su surgimiento embrionario dentro de algunas grandes firmas. Una de las conclusiones de su trabajo es que los encargados de regular la profesión judicial están de acuerdo en que es necesario moverse “... más allá del paradigma individualista que actualmente domina la regulación profesional y concentrarse en desarrollar estructuras auto-regulatorias dentro de los bufetes". 
de las Model Rules de la ABA que sostiene que "una prefesión juridical independiente es una fuerza importante para preservar la existencia de un gobierno sometido al Derecho, porque el abuso de la autoridad jurídica es desafiado de manera más expeditiva por una profesión cuyos miembros no dependen del gobierno para tener el derecho a ejercerla".

De esta manera la dependencia del abogado en relación con los deseos y preferencias del cliente se combina con la independencia de los abogados, a la hora de ejercer la profesión, de las regulaciones estatales. En este sentido la $\mathrm{ABA}$ parece ser un caso paradigmático. Ha ido tan lejos a la hora de defender la auto-regulación, como para sugerir que cualquier intento de reglar el ejercicio profesional que no provenga de una norma expresa dictada por el Congreso, debe ser respetuosamente desobedecida por los abogados ${ }^{36}$. La idea detrás de esta afirmación es que la conducta profesional idealmente sólo debería ser regulada por el colegio profesional y que este no es el caso sólo cuando existe una norma estatal expresa cuya literalidad no puede ser evitada de manera alguna.

Otra variante del ideal de auto-regulación es aquél que se realiza a través de los instrumentos del propio mercado. Existe una línea argumental que conduce desde la libertad como no-interferencia a la justificación del mercado como herramienta de regulación. El mercado no está constituido más que por el intercambio voluntario, libre de interferencias, de bienes y servicios. El caso de los servicios profesionales, se sostiene, no es una excepción, y lo que debe garantizar el Estado son los mismos extremos que deben ser garantizados en la transacción de cualquier otro bien o servicio. Siguiendo esta línea argumental, la regulación que protege a los consumidores es suficiente para garantizar el funcionamiento del mercado de los servicios legales. No es necesaria ninguna regulación específica-dictada por los órganos estatales o por los colegios profesionales- y cualquier intento adicional de reglar la conducta profesional es una vulneración a la libertad como no-interferencia. La defensa del mercado en base a la libertad como no-interferencia es completada con un argumento de eficiencia: cualquier intento de regulación centralizada será necesariamente inferior a la organización espontánea que surge del mercado ${ }^{37}$.

${ }^{36}$ Koniak, Susan, - Cohen, George, In Hell There Will Be Lawyers Without Clients or Law, en Rhode, D. L. (ed.), Ethics in Practice: Lawyer's Role, Responsibility and Regulation (Oxford, Oxford University Press, 2000), p. 182.

${ }^{37}$ HaYeK, cit. (n. 19), p. 21; el autor ha sido el principal defensor de este tipo de posiciones. Según su visión cualquier sistema de planificación central tendrá un enorme problema para recolectar información porque la información se encuentra dispersa y es difícil de adquirir. Un punto central en toda la obra de Hayek, que por supuesto se aplica a la regulación del ejercicio de la abogacía, es que el orden 
Adoptar una concepción negativa de la libertad también permite explicar por qué la ética profesional ha tendido a focalizarse en identificar y evitar los conflictos de intereses. Si el abogado es el defensor de la libertad del cliente, y esta es entendida como la posibilidad de éste de conducirse de acuerdo con sus intereses actuales o potenciales, es lógico que se vea como un problema de suma gravedad la posibilidad de que el abogado responda a intereses que no sean los de su cliente. Si el abogado representa intereses conflictivos a los de su cliente -incluidos los suyos propios- no existe ninguna garantía de que actúe como protector de la libertad de aquel.

Finalmente, en el paradigma que concibe a la libertad como nointerferencia la ética profesional es vista como una "ética de principios" en lugar de una "ética de virtudes". La razón de la resistencia a concebir al buen abogado como aquel que posee ciertos rasgos de carácter valiosos, en lugar de aquel que simplemente sigue las leyes, es que la idea de virtud se encuentra emparentada con la noción de libertad positiva y ésta con la de totalitarismo y perfeccionismo. La noción de virtud corporiza la idea de que existen ciertas partes de nosotros mismos que son más valiosas que otras y que las primeras deben gobernar a las últimas. La prudencia es más valiosa que la temeridad, el coraje más valioso que la cobardía, la misericordia es superior a la indiferencia, etc. Como se recordará, Berlin y quienes tienen una noción negativa de libertad, veían a esta forma de libertad positiva con recelo por dos motivos. En primer lugar, porque cuando se hacía el traslado del auto-gobierno individual al colectivo, se terminaba justificando la idea de que la porción supuestamente más valiosa de la sociedad ejercite el control sobre las menos valiosas y, en segundo lugar, lo haga para imponer un ideal humano dotado de ciertos rasgos de carácter.

Ahora bien, si esta es la visión que tienen de la virtud aquellos que conciben a la libertad de manera negativa, no es de extrañar que vean con reticencia cualquier intento de controlar el ejercicio profesional a través de la promoción en los abogados de ciertos rasgos de carácter que se consideran valiosos. La idea de que estos rasgos valiosos o virtudes van a ser identificados por la porción moralmente más elevada de la profesión, se les aparece como una puerta de ingreso al totalitarismo. Adicionalmente, que estos rasgos vayan a ser desarrollados a través de un programa de enseñanza o entrenamiento -por ejemplo en las escuelas de derecho- les parece un ejercicio intolerable de perfeccionismo. Frente a esta alternativa, la idea

puede surgir de manera espontánea sin que exista ningún regulador. Hayek veía con cierta frustración que la refutación de la falacia que había conducido en las ciencias naturales de constatar la existencia de orden a postular la existencia de un supremo diseñador, no hubiese tenido su réplica en las ciencias sociales (p. 59). 
de una ética profesional de reglas o principios surge como más segura y libre de riesgos.

Como no podría ser de otra manera, los vasos comunicantes que existen entre la concepción negativa de libertad y el abandono del ideal de jurista virtuoso son múltiples. La desconfianza en la libertad positiva es sólo uno de ellos. Otro es puesto de manifiesto por Kronman. Según éste tradicionalmente los jueces y abogados se preparaban para resolver los casos difíciles. Para hacerlo debían desarrollar la virtud de la sabiduría práctica que consistía en "...un sutil y refinado sentido del modo en que los principios generales (y por lo general conflictivos) de doctrina jurídica debían ser aplicados a las controversias concretas" ${ }^{38}$. La misma visión tenían los profesores de derecho que veían a su profesión como un ejercicio de sabiduría práctica que tenía por objeto contribuir a la misma tarea que llevaban adelante abogados y jueces. Esta visión, señala Kronman, cambió con un cultor de la libertad negativa: Thomas Hobbes. A partir de Hobbes el derecho dejó de ser visto como una rama de la sabiduría práctica y pasó a ser considerado como un conjunto de reglas. Consecuentemente, la tarea de los profesores de derecho dejó de ser percibida como una complementaria con la tarea de jueces y abogados. El estudio del derecho dejó de estar focalizado en el ejercicio y desarrollo de una virtud y pasó a ser una ciencia focalizada en el conocimiento de normas ${ }^{39}$.

Si el derecho no es más que un conjunto de reglas cuya aplicación sólo requiere conocimiento, la tarea que realizan los profesores de derecho es una especie de ciencia. Es un tipo de conocimiento teórico que no requiere ningún tipo de sabiduría práctica o virtud. Consecuentemente, un buen abogado es simplemente aquel que conoce las reglas -incluidas las que se aplican a su propia conducta- y las sigue. Del mismo modo que el buen

${ }^{38}$ Kronman, cit. (n. 10), p. 21.

${ }^{39}$ Kronman, cit. (n. 10), p. 175. El autor continúa esta línea de pensamiento iniciada por Hobbes, a través de Chirstopher Langdell, el realismo jurídico, el análisis económico del derecho y los estudios críticos. En todos los casos el estudio del derecho es visto como una ciencia. Langdell, fundador del método de casos, veía al derecho como un conjunto de reglas y principios que debían ser descubiertos a través del estudio de las decisiones judiciales. Los realistas, a pesar de criticar las ideas de Langdell, continuaron aceptando su principio de que debía construirse una teoría del derecho a través de métodos no adquiridos por la experiencia sino a través de la investigación académica (p. 196). La misma idea de que el estudio del derecho debe consistir en encontrar alguna especie de principio oculto que subyace a la actividad práctica y particularista llevada adelante por los jueces, se encuentra presente en el análisis económico del derecho y los estudios críticos. Los primeros evalúan el derecho desde el principio de eficiencia, los segundos desde su capacidad de sostener o desestabilizar las jerarquías sociales injustas. 
juez es aquel que conoce las reglas jurídicas y las aplica. Todo rasgo de carácter es borrado por completo de la escena.

\section{CONCLUSIÓN}

El rol del abogado se encuentra cruzado por diferentes lealtades en tensión. Los modos de articular estas lealtades son múltiples, así como lo son las razones que los justifican. Esta articulación, adicionalmente, configura los rasgos específicos que tiene el rol de abogado en una determinada cultura legal. En este trabajo se ha mostrado cómo si se emplea la idea de libertad como no-interferencia para dar contenido a las dos exigencias de lealtad que definen el rol de abogado -la referida a los intereses del cliente y la referida a los intereses colectivos o públicos-aparece una imagen del ejercicio profesional semejante a la que se encuentra presente en nuestra cultura legal: el abogado debe llevar adelante una "celosa defensa" de los intereses del cliente dentro de los límites de la ley que es equivalente a la defensa de su libertad, cumple meramente una tarea de asistencia técnica, al defender los intereses privados contribuye a la realización de los intereses públicos o a la realización de la justicia, toda regulación al ejercicio profesional es vista con recelo, y la ética profesional es vista como una "ética de principios o reglas".

Aun quienes creen, como es mi caso, que esta manera de concebir el rol profesional es defectuosa y que existe una manera más adecuada de resolver las exigencias de lealtad aparentemente conflictiva que inciden sobre el abogado, harían bien en percibir que la misma descansa sobre un modo específico de concebir a la libertad como no-interferencia. Los diferentes elementos que configuran la manera dominante de caracterizar el rol profesional no son un conjunto inconexo que se justifican en consideraciones pragmáticas, en el mejor de los casos, o en vicios e intereses espurios, en el peor. Todos se encuentran fundados en consideraciones morales referidas a una manera de entender la libertad.

Mostrar las raíces profundas que tiene este modo de ver la tarea de los abogados permite comprender lo arraigado que se encuentra. La forma de concebir el ejercicio profesional no puede ser modificada simplemente alterando las reglas presentes en un código, o diseñando novedosos mecanismos de control. Cualquier que se sienta incómodo con los contornos que ha adquirido la profesión deberá tener presente que sus raíces se extienden hasta un modo de concebir la libertad, la política, el auto-gobierno y que cualquier intento de modificación deberá ser lo suficientemente profundo como para alterarlas. Mientras esta tarea no se acometa todo intento de 
reforma del rol profesional será sólo una especie de operación cosmética por la que se cambia algo para que todo siga igual.

\section{BiBLIOGRAFÍA}

BerLin, Isaiah, Two Concepts of Liberty, en Liberty (Oxford, Oxford University Press, 2002).

Chambliss, Elizabeth - Wilkinks, David, Promoting Ethical Infrastructure in Large Law Firms: A Call for Research and Reporting, en Hofstra Law Review 30 (2002), 3.

Frankel, Marvin, The Search for Truth: An Umpireal View, en University of Pennsylvania Law Review 123 (1975).

Freedman, Monroe, Judges Frenkiel's Searches for Truth, en University of Pennsylvania Law Review 123 (1985).

Fuller, Lon, The Adversary System: Talks on American Law (New York, Vintage Books, 1961).

Glendon, Mary Ann, A Nation Under Lawyers (Cambridge, Harvard University Press, 1996).

Hampshire, Stuart, Justice is Conflict (Princeton, Princeton University Press, 2001). HAYEK, Friedrich, The Constitution of Liberty (London, Routledge \& Keegan Paul, 1960).

HAYEK, Friedrich, Law, Liberty and Legislation (Chicago, University of Chicago Press, 1973), I.

Hobbes, Thomas, Leviathan (New York, Touchstone, 1997).

Keller, Simon, The Limits of Loyalty (Cambridge, Cambridge University Press, 2007).

Koniak, Susan - Cohen, George, In Hell There Will Be Lawyers Without Clients or Law, en Rhode, D. L. (ed.), Ethics in Practice: Lawyer's Role, Responsibility and Regulation (Oxford, Oxford University Press, 2000).

Kronman, Anthony, The Last Lawyer: Failing ideals of the Legal Profession (Cambridge, Harvard University Press, 1995).

Lerman, Lisa - Schrag, Philip, Ethical Problems in the Practice of Law (20 edición, New York, Aspen Publishers, 2008).

Luban, David, Legal Ethics and Human Dignity (Cambridge, Cambridge University Press, 2007).

Oppenheim, Felix, Dimensions of Freedom: An Analysis (New York, St. Martin's Press, 1961).

Pеттіт, Philip, The Instability of Freedom as Noninterference: The Case of Isaiah Berlin, en Ethics 121 (2011).

RaWLS, John, A theory of justice (Cambridge, Harvard University Press, 1999).

Rhode, Deborah, Ethics in Practice, en Ella misma (ed.), Ethics in Practice: Lawyer's Role, Responsibility and Regulation (Oxford, Oxford University Press, 2000).

Seleme, Hugo, Etica de las Creencias y Defensa Legal, en Salassa Boix, R. - Fatauros, C. (eds.), Instituciones Públcias y Moralidad Política (Córdoba, Ciencia, Derecho y Sociedad UNC, 2014).

Shaffer, Thomas - Cochran, Robert., Lawyers, clients and moral responsibilit (St. Paul, West Publishing, 1994).

Simon, William, The Practice of Justice: A Theory of Lawyer's Ethics (Cambridge, Harvard University Press, 1998).

SteIner, Hillel, An Essay on Rights (Oxford, Blackwell, 1994). 